\title{
ESCOLA PARA ALÉM DO DIGITAL: REFLEXÕES SOBRE OS ESTÁGIOS NA FORMAÇÃO DOCENTE EM MÚSICA
}

\author{
Beyond digital school: reflections on \\ preservice music teacher education
}

\author{
La escuela más allá de lo digital: reflexiones \\ sobre las prácticas en la formación del \\ profesorado de música
}

\author{
Teresa Mateiro \\ Universidade do Estado de Santa Catarina \\ teresa.mateiro@udesc.br \\ SANDra Mara da CUnHa \\ Universidade do Estado de Santa Catarina \\ sandra.cunha@udesc.br
}

\begin{abstract}
Resumo: Este artigo tem como objeto os estágios curriculares supervisionados do curso de Licenciatura em Música da Universidade do Estado de Santa Catarina (Udesc). O objetivo é o de lançar reflexões sobre estágios não presenciais, evidenciando as desafiantes condições humanas e pedagógicas colocadas pela pandemia da Covid-19 e os caminhos encontrados para dar prosseguimento à formação de licenciandos. Os referenciais teóricos se encontram na área da educação e, mais especificamente, na formação docente. Priorizamos publicações e conferências que têm tematizado a ação e formação em tempos de incerteza, que pensam a escola e o seu papel para além da pandemia, bem como autores que estudam sobre tecnologias digitais e aulas online. A discussão girou em torno da importância de pensar o estágio e a educação não presencial, a explosão das tecnologias de informação e comunicação, os decorrentes processos de ensino e aprendizagem, e as dimensões do modelo atual de escola. Destacamos que é necessário abandonar a lógica disciplinar, construir novas formas para pensar a presença e a educação sem distância, desenvolver estratégias integradoras entre as diferentes gerações de tecnologias de linguagem e de comunicação, e transformar as escolas em poderosos cenários de aprendizagem. Ressaltamos a situação emergencial dos estágios remotos para manter a continuidade da formação docente e reafirmar o nosso compromisso com a educação. Compromisso de natureza ética porque a escola pública é direito fundamental de crianças e jovens, e junto à universidade pública e gratuita são espaços nos quais se aprende e se exercita a colaboração e a participação cidadã.
\end{abstract}

Palavras-chave: Tecnologias. Processos de aprendizagem. Licenciatura em Música. Pedagogia da autonomia.

\begin{abstract}
This article has focused on preservice teacher education in the Degree in Music of Santa Catarina State University (Udesc). The objective is to encourage reflection on non-face-to-face preservice education activities, highlighting the challenging human and pedagogical conditions posed by the Covid-19 pandemic and the paths available to advance the education of undergraduate students. The theoretical frameworks are from the field of Education and, more specifically, Teacher Education. Priority has been given to publications and conferences that have focused on action and education in times of uncertainty, which take into account schools and their role after the end of the pandemic, as well as to authors who study digital technologies and online classes. The discussion revolved around the importance of thinking about non-face-to-face preservice music teacher education and classroom education, the boom in information and communication technologies, the resulting teaching and learning processes, and the dimensions of the current school model. We highlight that one needs to abandon disciplinary logic, create new ways to think about presence and non-distance education, develop integrative strategies between different generations of language and communication technologies, and transform schools into powerful learning scenarios. Also, we emphasize the emergency
\end{abstract}


situation involving remote preservice teacher education activities to maintain the continuity of teacher education and to reaffirm our commitment to education. It is an ethical commitment because stateowned schools are a fundamental right of children and young people and, together with state-owned universities, they are spaces in which collaboration and citizen participation are learned and exercised.

Keywords: Technologies. Learning processes. Degree in music. Pedagogy of autonomy.

Resumen: El objeto de este artículo son las prácticas curriculares supervisadas en el Programa de grado en Música de la Universidad Estatal de Santa Catarina (Udesc). El objetivo es lanzar reflexiones sobre las prácticas no presenciales, evidenciando las desafiantes condiciones humanas y pedagógicas que la pandemia Covid-19 plantea y los caminos encontrados para continuar la formación de estudiantes de grado. Los marcos teóricos se encuentran en el ámbito de la Educación y, más concretamente, en la Formación del Profesorado. Hemos priorizado publicaciones y conferencias que se han centrado en la acción y la formación en tiempos de incertidumbre, que piensan en la escuela y su papel más allá de la pandemia, así como los autores que estudian acerca de las tecnologias digitales y clases en línea. El debate giró en torno a la importancia de reflexionar acerca de las prácticas y de la educación no presencial, de la explosión de las tecnologías de información y comunicación, de los consecuentes procesos de enseñanza y aprendizaje y de las dimensiones del modelo escolar actual. Destacamos que es necesario abandonar la lógica disciplinar, construir nuevas formas de pensar la presencia y la educación sin distancia, desarrollar estrategias integradoras entre diferentes generaciones de tecnologías del lenguaje y comunicación, y transformar las escuelas en potentes escenarios de aprendizaje. Señalamos la situación de emergencia de las prácticas a distancia para mantener la continuidad de la formación docente y reafirmar nuestro compromiso con la educación. Compromiso de carácter ético porque la escuela pública es un derecho fundamental de la infancia y de la juventud $\mathrm{y}$, junto con la universidad pública y gratuita, son espacios dónde se aprende y se ejerce la colaboración y la participación ciudadana.

Palabras clave: Tecnologias. Procesos de aprendizaje. Formación del profesorado de música. Pedagogía de la autonomia.

\section{INTRODUÇÃO ${ }^{1}$}

A escola que vivenciamos como alunas e professoras e a universidade onde trabalhamos são referências de uma realidade distante do cenário provocado pelo vírus Sars-CoV-2, que causa a doença Covid-19, assim denominada pela Organização Mundial da Saúde (OMS). Diante dessa nova situação, esses lugares de pensar e fazer educação tiveram que fechar suas portas e interromper as atividades presenciais a partir do mês de março de 2020. Depois de um período inicial de muitas incertezas, ao prepararmos a retomada das aulas, muito do que sabíamos e conhecíamos sobre o fazer escola teve que ser repensado pela impossibilidade de professores, estudantes e toda a equipe que compõe as instituições de ensino estarem juntos do modo como havia sido até então.

$\mathrm{Na}$ busca por alternativas de ação e referências para nos ajudar a pensar caminhos, encontramos apoio na afirmação de Nóvoa $(2020)^{2}$ para seguirmos em frente: "As universidades e nós, professores, não podemos ficar parados, indecisos e sem saber o que fazer em tempos como esses que estamos vivendo." Nessa fala, o autor reafirma a importância do papel docente nesse momento, convidando-nos ao exercício da criatividade, para buscar soluções, e da ética e do compromisso que temos com as práticas, além do que já dizíamos antes da pandemia:

\footnotetext{
1 Uma versão deste artigo foi apresentada no XIX Encontro Regional Sul da Abem (Mateiro; Cunha, 2020).

2 Transcrição livre extraída da webconferência, promovida pela Secretaria de Educação de Santa Catarina e o Instituto lung, realizada no dia 23/06/2020.
} 
Fazer das universidades o lugar de construção de conhecimento, lugar de diálogos entre a universidade e as escolas, entre professores, entre professores e gestores, entre pesquisadores, e desses com os responsáveis pelas politicas públicas, municipais e estaduais (Nóvoa, 2020).

Foi nesse quadro de distanciamento social que tivemos de repensar as disciplinas de Estágio Curricular Supervisionado do curso de Licenciatura em Música da Universidade do Estado de Santa Catarina (Udesc). Fomos desafiadas enquanto professoras dessas disciplinas a buscar novas proposições para as aulas, para as orientações e atuações nos campos, nos quais os estudantes recém haviam feito as primeiras observações. As aulas remotas se colocaram como a possibilidade para a retomada do semestre letivo, na universidade e nas escolas de educação básica, situação que instituiu uma nova realidade educativa a ser enfrentada. É sobre essa temática que este artigo se constrói, com o objetivo de lançar reflexões sobre estágios não presenciais, evidenciando as desafiantes condições humanas e pedagógicas colocadas pela pandemia, e os caminhos encontrados para dar prosseguimento à formação de licenciandos em música.

Essa situação, apesar de nova, no sentido de os estágios não poderem ser desenvolvidos em um espaço físico educativo - as escolas, locais onde as relações humanas são essenciais, atualizam o debate acerca de tecnologias e processos de aprendizagem por meio de aulas online e da diferença entre essas e o ensino a distância. Para além dessas questões trazemos para as discussões um principio que consideramos fundamental na formação docente em música: considerar, na preparação das atuações nos estágios, os contextos a que as crianças, jovens e docentes pertencem, de modo que o conhecimento musical esteja em relação com os sujeitos para os quais as aulas são planejadas.

Para refletir e discutir sobre a temática proposta, buscamos referenciais teóricos na área da educação e, mais especificamente, na formação de professores, em publicações e conferências que têm tematizado a ação e a formação docente em tempos de incertezas e que também pensam a escola e o seu papel para além da pandemia (Nóvoa, 2020; Nóvoa; Alvim, 2020; Tardif, 2020), bem como em autores que vêm pensando sobre tecnologias digitais e aulas online como, por exemplo, Santaella (2010) e Figueiredo (2016).

Alguns desses estudiosos, como veremos mais adiante, tanto nos instigam a falar sobre os impactos da pandemia em nossas aulas e cursos quanto nos convocam à ação, com a proposição de novos formatos e perspectivas para fazer educação musical na escola e na universidade. Ao pensarmos com esses autores e a partir deles, reafirmamos que os estágios supervisionados em música, ainda que estejam sendo realizados de modo remoto, não podem perder de vista que o seu lugar de acontecimento privilegiado é no espaço físico das escolas. Defendemos a escola pública como um lugar de convergência de saberes, espaço de construção de conhecimento, promotor da autonomia e da participação cidadã. 


\section{TECNOLOGIAS E PROCESSOS DE APRENDIZAGEM}

A pesquisa e inovação pedagógicas, antes mesmo da pandemia, já apontavam para a explosão das tecnologias de informação e comunicação como responsáveis por um novo conceito de aprendizagem e de processos de ensino. As tecnologias comunicacionais, conforme Santaella (2010, p. 20), fizeram emergir "processos de ensino-aprendizagem baseados na tecnologia do livro, na educação a distância, na aprendizagem em ambientes virtuais e por meio dos dispositivos móveis".

O conceito tradicional de educação nasce das mídias impressas, o livro, explica Santaella (2010, p. 20). A educação a distância relaciona-se ao modelo educacional próprio das mídias massivas, e as mídias computacionais ou digitais estão mais associadas ao modelo de educação online ou ambientes virtuais de aprendizagem (AVA), continua a autora. No novo quadro de distanciamento social que vivenciamos surge outra terminologia - aulas remotas, confirmada pela Portaria n ${ }^{\circ} 343$ do Ministério da Educação, alterada pela 345 (Brasil, 2020a), que dispõe sobre a substituição das aulas presenciais por aulas remotas enquanto durar a pandemia da Covid-19.

O Conselho Nacional de Educação (CNE), em 28 de abril de 2020, aprovou "as diretrizes para orientar escolas da educação básica e instituições de ensino superior durante a pandemia do coronavirus" (Estrella; Lima, 2020). Desse modo, as aulas presenciais foram substituídas temporariamente por aulas remotas, como uma solução emergencial para reduzir os prejuizos nos calendários acadêmicos e minimizar os impactos na aprendizagem dos estudantes. Mesmo antes dessas decisões governamentais professores universitários já estavam trabalhando nessa modalidade, demonstrando que podem agir com autonomia e fora das instituições, como analisa Tardif (2020). ${ }^{3}$

Entretanto, para fazer essa mudança necessária à manutenção da continuidade pedagógica possivel, tivemos que recorrer a artificios tecnológicos que já tínhamos à disposição na universidade, como a plataforma de apoio à ação pedagógica docente, dentre outras que foram utilizadas por iniciativas individuais dos professores. Do lugar de um dos recursos de ensino, as salas virtuais abrigadas em plataformas têm sido um espaço de adaptação da mediação didática e de manutenção da relação pedagógica de forma síncrona entre professores-estudantes e estudantes-estudantes.

Um novo mundo educativo caiu sobre nossas cabeças e nos convocou a agir rapidamente, mas também a pensar sobre ele de modo mais detido. Uma das questões que se colocou foi a de refletir sobre: qual a diferença entre aulas remotas e educação a distância? Santaella (2010, p. 20) esclarece que os resultados do modelo a distância mostram que há uma tendência "a copiar para as telas ou rádios, de maneira artificial, os procedimentos de ensino que são próprios das atividades presenciais". A aprendizagem ocorre por meio de

\footnotetext{
3 Entrevista concedida ao Portal Cenpec, 2020.
} 
processos passivos, uma vez que a educação a distância está entre as mídias massivas como as impressas, o rádio e a televisão.

Com isso, podemos dizer que são visões tradicionais de educação inspiradas na cultura industrial que, conforme Figueiredo (2016, p. 19), "encaram o digital como essencialmente instrumental e tendem a ignorar a imensa mutação sociocultural e económica que vivemos". O que temos observado nas instituições de ensino é que a tecnologia digital, de maneira geral, não tem tido uma função educativa. O desafio que se coloca, na análise de Figueiredo (2016, p. 20), "é o de assegurar que os jovens evoluam, do seu estatuto de meros consumidores, para o estatuto de utilizadores esclarecidos, e deste para o estatuto de criadores e participantes ativos".

As mídias digitais - internet e suas diversas ferramentas, redes ponto a ponto, ${ }^{4}$ softwares e telefones celulares, implicam o agenciamento e a participação do aprendiz, como aponta Lemos (2007, p. 124). Elas, continua o autor, apresentam novas funções que "permitem a personalização, a publicação e a disseminação de informação de forma não controlada" (Lemos, 2007, p. 125) e qualquer indivíduo, pela primeira vez, pode produzir e publicar informação em tempo real. Estamos, assim, diante do acesso livre e ubíquo do conhecimento.

De acordo com Santaella (2010, p. 21), "inaugura-se uma modalidade de aprendizagem que é tão contingencial, inadvertida e não deliberada que prescinde da equação ensino-aprendizagem caracterizadora dos modelos educacionais e das formas de educar". Corroborando Figueiredo (2016, p. 21), presenciamos a transformação de um modelo pedagógico centrado no professor, isto é, na explicação, para um modelo centrado na autonomia de quem aprende.

Os sentidos de dependência e obrigação são substituídos por iniciativa e responsabilidade pela sua própria formação. No nosso entender, eles são desafiadores porque requerem de docentes a orientação de discentes, tanto na busca de conhecimento - mais do que informação - como na atenção para a necessária auto-organização que o espaço-tempo online requer nesse novo modo de ensino-aprendizagem por meio de aulas remotas.

Essa pedagogia formativa impõe-se com a necessidade de migrar do espaço físico das escolas, onde se estabelecem relações de vida e se constroem conhecimentos, para os espaços privados familiares. Assim, a situação da educação remota emergencial acentuou o que não é novo: que somos um país de grandes desigualdades no acesso à educação. Tardif (2020), ao falar sobre esse problema, ressalta que muitos estudantes e professores, no mundo inteiro, foram abandonados, tanto por suas instituições como pelos órgãos educativos reguladores, devido às diferenças sociais e econômicas acentuadas por essa crise de saúde sem precedentes em nossa história recente.

No caso das disciplinas de Estágio Curricular Supervisionado, o cenário se agravou porque a maioria dos estudantes estava começando seus estágios

\footnotetext{
4 Tradução livre de peer to peer (P2P).
} 
em escolas de educação básica pertencentes a redes públicas de ensino. Nessas, o impacto provocado pelo distanciamento social ficou também evidenciado porque crianças e jovens têm mostrado dificuldades e falta de condições pessoais e materiais que impedem seu acesso às aulas e atividades que têm sido realizadas de modo remoto.

Conforme Arruda (2020, p. 7), a escola "é um dos espaços sociais em que há maiores trocas e mobilidades de sujeitos de diferentes faixas etárias, portanto, representa espaço de maior probabilidade de contaminação em massa". Assim sendo, as tecnologias tornaram-se a principal solução para a manutenção das conexões escolares, considerando a excepcionalidade do momento e suas graves consequências. O autor destaca:

Decidir pela inoperância da escola poderia significar não só a fragilização desse espaço institucional, mas também promover amplo crescimento de desigualdades diversas, pois estar longe da escola, mas em contato com cotidiano com suas ações pedagógicas é menos danoso do que não estar em qualquer contato com a escola ao longo de muitos meses de confinamento (Arruda, 2020, p. 8).

Os múltiplos desafios elencados se instalaram no nosso trabalho de professoras formadoras, junto à equipe de professores que compõe esse conjunto disciplinar, que envolve também as orientações de estagiários em seus diversos campos. Como transformar o que era anteriormente um recurso tecnológico de apoio à ação docente em um veículo principal para a continuidade dessas disciplinas, sabendo que essas dependem de campos de atuação para os estudantes que, nessa nova realidade, deixaram de existir presencialmente?

Essas são algumas incertezas da nova realidade, do "novo normal". Contudo, temos algumas certezas: o livro, a educação a distância, a aprendizagem em ambientes virtuais e a aprendizagem ubíqua não substituem uns aos outros, eles não são equivalentes. Retornando a Santaella (2010, p. 21), essas formas de aprendizagem se complementam por seus potenciais e limites que lhes são próprios, tornando o processo educativo muito mais rico e dinâmico. Fica claro, assim, que as aulas remotas são uma resposta a uma situação emergencial.

\section{ESTÁGIOS NÃO PRESENCIAIS}

Os Estágios Curriculares Supervisionados do curso de Licenciatura em Música da Udesc são oferecidos nos dois últimos anos do curso e seguem a seguinte dinâmica: no primeiro ano, eles acontecem em espaços de ensino e aprendizagem não escolares - como corais, bandas, projetos sociais em bairros comunitários, hospitais e estúdios - e, no segundo ano, no contexto escolar. Entretanto, há certa flexibilidade para a escolha dos campos, uma vez que estudantes matriculados nos Estágios I e II podem optar por realizar o estágio em escolas públicas de educação básica. 
Em 2020 essa foi a principal opção, pois grande parte dos campos não escolares não deram continuidade às suas atividades desde março, quando se iniciou o isolamento social. Também foi esse o caso dos estágios que seriam desenvolvidos na etapa da educação infantil. Assim, boa parte dos estagiários trabalharam com professores de música em turmas do $3^{\circ}$ ao $9^{\circ}$ ano do ensino fundamental de quatro escolas públicas de educação básica, municipais e federais, e em turmas de ensino médio de institutos federais. É importante ressaltar que os estágios foram realizados individualmente e em dupla.

Apesar das limitações impostas pela ausência dos encontros presenciais dos estagiários com crianças e jovens em cada uma das escolas, pensamos que os primeiros teriam diante de si uma nova aprendizagem: a de atuar junto a professores, de forma recíproca e colaborativa, para manter a escola pública viva. A dinâmica no planejamento das atividades foi praticamente a mesma em todos os campos: gravação de vídeos e áudios e elaboração de materiais didáticos digitais. Em algumas escolas os professores de música postavam as atividades em plataformas especificas de ensino, e em outras promoveram aulas e atividades sincronas, semanal ou quinzenalmente.

O planejamento dos estagiários foi acompanhado pelos professores das disciplinas ${ }^{5}$ de Estágio Curricular Supervisionado, assim como pelos orientadores ${ }^{6}$ e supervisores. ${ }^{7}$ As orientações semanais foram realizadas de modo remoto por meio das plataformas Google Meet, Zoom e Teams. Os orientadores criaram grupos por campo de estágio no aplicativo WhatsApp, para facilitar a comunicação entre todos, incluindo os professores supervisores. Portanto, as orientações, além de ocorrerem de forma individual e em duplas, foram também realizadas com o grupo de estagiários que se encontrava no mesmo campo de estágio e, consequentemente, tinham o mesmo professor supervisor.

Ações paralelas foram oferecidas aos estagiários visando dar suporte pedagógico para esse diferente modo de aprender e ensinar, como: professores convidados relataram como estavam trabalhando de modo remoto; sites de escolas que disponibilizam atividades para consulta e análise foram indicados; a universidade ofereceu curso de Moodle para os acadêmicos e uma das escolas incluiu os estagiários no curso da plataforma direcionada aos professores da instituição; um estudante de mestrado com formação em audiovisual orientou, voluntariamente, como realizar gravação e edição de vídeos; e um grupo de pesquisa ofereceu um curso de formação docente para auxiliar o planejamento de projetos criativo-musicais frente aos desafios impostos pela suspensão das aulas presenciais.

\footnotetext{
5 A resolução de ocupação docente da Udesc estabelece que cada professor pode ter até dez orientandos, sejam eles de estágio, iniciação científica, mestrado ou doutorado. Por isso, a necessidade de mais professores orientadores.

6 Professores que acompanham os estágios e que nem sempre são os professores das disciplinas, em virtude do número de estudantes matriculados por turma e a disponibilidade de carga horária dos professores da área de estágio.

7 Professores de música atuantes em escolas de educação básica.
} 
Vale destacar, ainda, a criação de material didático e a organização de recitais didáticos por grupos de estagiários. O desafio proposto foi o de pensar e preparar um recital para além daquele dado à apresentação formal de uma obra musical para uma plateia (Ekedahl; Mateiro, 2015, p. 4). A dificuldade foi maior porque, sendo o recital gravado em vídeo e disponibilizado no YouTube, não haveria essa tradicional plateia. De qualquer modo, é possivel ultrapassar a atitude da escuta passiva porque a natureza é pedagógica e aproximadora. Os estagiários ficaram online em data e hora marcada para, após o vídeo, conversar com quem assistiu.

\section{INCERTEZAS E APOSTAS}

Como professoras, fomos confrontadas com a "incerteza do real", um dos sete saberes necessários à educação do futuro, conforme postulado por Morin (2000, p. 85). O antropólogo, sociólogo e filósofo francês afirma que a realidade não é outra coisa senão a nossa ideia de realidade e, por isso, "importa não ser realista no sentido trivial (adaptar-se ao imediato), nem irrealista no sentido apontado (subtrair-se às limitações da realidade); importa ser realista no sentido complexo: compreender a incerteza do real, saber que há algo possivel ainda invisível ao real" (Morin, 2000, p. 85).

A interpretação que tínhamos [e temos] da realidade no contexto da pandemia era que se, por um lado, as instituições ficariam fechadas por um longo tempo, por outro, como educadoras, não poderiamos ficar paradas e indecisas, deixando a ação docente distanciada dos estudantes. Era possível fazer algo, entretanto, qualquer decisão seria uma aposta e, como diz Morin (2000, p. 86), "na noção de aposta há a consciência do risco e da incerteza". Apostamos que os licenciandos poderiam realizar seus estágios curriculares supervisionados de modo não presencial acompanhando professores de música que atuam em escolas públicas de educação básica, em suas árduas tarefas de planejar aulas e atividades por meio de mecanismos digitais.

Essa ação intencional e esse compromisso com as práticas implicou cautela, uma vez que a base legal era necessária para apoiar a "ecologia da ação" (Morin, 2000, p. 87) e, portanto, foram considerados os seguintes documentos: Portaria MEC n ${ }^{\circ}$ 544, de 16 de junho de 2020; 8 Parecer CNE/CP n ${ }^{\circ}$ 5/2020; ${ }^{9}$ Resolução CEE/SC n 009 de 19 de março de 2020; ${ }^{10}$

\footnotetext{
8 “Dispõe sobre a substituição das aulas presenciais por aulas em meios digitais, enquanto durar a situação de pandemia do novo coronavírus - Covid-19, e revoga as Portarias MEC no 343, de 17 de março de 2020, no 345, de 19 de março de 2020, e no 473, de 12 de maio de 2020" (Brasil, 2020c).

9 "Reorganização do Calendário Escolar e da possibilidade de cômputo de atividades não presenciais para fins de cumprimento da carga horária mínima anual, em razão da Pandemia COVID-19" (Brasil, 2020b).

10 "Dispõe sobre o regime especial de atividades escolares não presenciais no Sistema Estadual de Educação de Santa Catarina, para fins de cumprimento do calendário letivo do ano de 2020, como medida de prevenção e combate ao contágio do Coronavírus (COVID-19)" (Santa Catarina, 2020a).
} 
Resolução CEE/SC no 049 de 22 de junho de 2020; ${ }^{11}$ Parecer CEE/SC $\mathrm{n}^{\circ} 222 .{ }^{12}$ De acordo com Morin, a ecologia da ação "é levar em consideração a complexidade que ela supõe, ou seja, o aleatório, acaso, iniciativa, decisão, inesperado, imprevisto, consciência de derivas e transformações" (Morin, 2000,p. 87). Desse modo, há um princípio de incerteza fundamental que não pode prever as consequências futuras dessa ação.

O risco e a precaução compreendem o princípio da incerteza, conforme explica Morin (2000, p. 88). Apesar de existir contradição entre o princípio do risco e da precaução, os dois são necessários em qualquer ação. O nosso compromisso, como professoras formadoras, continua sendo o exercício da ética tal como proposto por Nóvoa (2020), na promoção de diálogos entre universidade e escolas, professores e gestores, professores e pesquisadores e entre os responsáveis pelas politicas públicas. Estamos cientes de que essa situação emergencial está longe de ser a solução ideal para a realização de estágios no contexto educacional e os seus efeitos a longo prazo são imprevisiveis.

Com isso, parafraseando Nóvoa (2020), queremos dizer que a escola física é indispensável para os estagiários e alunos em idade escolar, os professores são indispensáveis, assim como o ato pedagógico e as relações humanas. Tardif (2020), em entrevista concedida ao Portal Cenpec, afirmou: "A escola existe unicamente pelas interações humanas entre os professores com seus alunos [...] e nós não podemos substituir essas interações humanas cotidianas pelas tecnologias [...]. Esta é a primeira lição que podemos tirar dessa crise." Nessa mesma perspectiva, Nóvoa (2020) se expressou de modo imperativo: "Esqueçam todas as ilusões, todas as miragens que vos poderiam levar a transformar a educação num ato digital ou num ato a distância. Isso não existe. A escola é central e os professores são centrais."

\section{ESCOLA PARA ALÉM DO DIGITAL}

Três dimensões do modelo que temos hoje de escola e que a pandemia veio a confirmar, e ainda requerem discussão com vista a mudanças, são discutidas por Nóvoa e Alvim (2020, p. 2). Primeiro, não faz mais sentido manter o contrato social que atribui a responsabilidade da educação das crianças somente à escola. É preciso reconhecer os processos educacionais dentro e fora do contexto escolar, por meios formais, informais e não formais (ver Santaella, 2010). ${ }^{13}$ A fronteira entre o escolar e o não escolar, de acordo com Pérez Gómez (2015, p. 29), "já não é definida pelos limites de espaço e do

\footnotetext{
11 “Dá nova redação ao art. 2o e revoga o § 4ㅇ do art. 3o da Resolução CEE/SC no 009/2020 e aplica ao Sistema Estadual de Educação de Santa Catarina o disposto no Parecer CNE/CP no 5/2020" (Santa Catarina, 2020c).

12 "Consulta sobre a possibilidade de continuidade dos estágios obrigatórios dos cursos de licenciaturas adotando-se atividades não presenciais no contexto da pandemia, de acordo com o que as redes estão ofertando" (Santa Catarina, 2020b).

${ }^{13}$ A autora relaciona a educação formal, informal e não formal aos saberes e habilidades associadas ao computador, à educação a distância, à educação online e à aprendizagem ubíqua.
} 
tempo da escola, existe muito de 'não escola' no horário escolar e há muito 'de escola' no espaço e tempo posterior ao horário escolar".

Na segunda dimensão, Nóvoa e Alvim (2020, p. 2), refletem sobre a necessidade de transformar a estrutura organizacional da escola fundamentada na lógica de: salas de aula e outros espaços que delimitam a circulação, mobiliário escolar, controle do tempo, papel dos professores, currículos e avaliação da aprendizagem, alunos agrupados por nível etário, recreio, tarefas e disciplinas. Desde a LDB de 1996, novas formas de organização escolar são possíveis e, assim, já temos no Brasil as chamadas escolas democráticas - livres, alternativas, progressistas. ${ }^{14}$

Essas escolas apresentam características bastante semelhantes às apontadas por Nóvoa e Alvim (2020, p. 2), como: ambientes acolhedores onde seja possivel o estudo individual e em grupo; projetos coletivos e colaborativos, presenciais e não presenciais; relações não hierárquicas entre estudantes e educadores; acompanhamento de docentes; discussões com um ou mais professores no desenvolvimento de projetos de pesquisa. Destacamos também o trabalho desenvolvido por José Pacheco na célebre Escola da Ponte em Portugal e em algumas escolas brasileiras. ${ }^{15} \mathrm{O}$ professor há muitos anos defende escolas sem horários, turmas, anos, testes, exames e reprovações (ver Pacheco, 2012, 2014).

O foco no estudo é a terceira dimensão apresentada por Nóvoa e Alvim (2020, p. 2). São necessárias "pedagogias que valorizem a diversidade de métodos e modalidades de estudo e trabalho" (Nóvoa; Alvim, 2020, p. 5), que ultrapassam a ideia de assistir a uma aula. É essencial substituir a atitude passiva de alunos sentados nas "carteiras escolares" para um lugar de pesquisa ativa para o conhecimento. Ação colaborativa e autonomia na produção de conhecimento pedagógico e curricular são dois aspectos cruciais para os professores. Os autores sublinham:

As melhores respostas à pandemia foram o resultado da colaboração entre grupos de professores, da mesma escola e de diferentes escolas, que puderam apresentar ideias e projetos inovadores, mantendo articulação com os alunos e conseguindo mantê-los mobilizados do ponto de vista de conhecimento, aprendizagem e educação (Nóvoa; Alvim, 2020, p. 5).

Essas características de uma pedagogia da autonomia, assim já denominada por Paulo Freire, exigem uma escola que prepare cidadãos independentes, inovadores, curiosos, inquietos, indagadores, críticos, afirmativos, colaborativos, comunicativos, persistentes, criativos, imaginativos e artísticos (Figueiredo, 2016, p. 19; Freire, 2011, p. 24-87; Pérez Gómez, 2015, p. 77). Para isso, de acordo com os autores, faz-se necessário pensar em abordagens

\footnotetext{
${ }^{14}$ Ver Singer (2008, 2015a, 2015b).

15 Projeto Âncora (SP), Escola Municipal de Ensino Fundamental Presidente Campos Salles (SP), Escola Municipal de Ensino Fundamental Desembargador Amorim Lima (SP), entre outras.
} 
orientadas para viver e atuar autonomamente, viver e conviver democraticamente em grupos humanos cada vez mais heterogêneos, e transformar a enxurrada desorganizada e fragmentada de informações em conhecimento e sabedoria.

Figueiredo (2016, p. 21) menciona a aprendizagem baseada em projetos, a aprendizagem mista, as aulas invertidas e a coavaliação. Especificamente, sobre a formação de professores de música, Mateiro (2018, p. 108) discute bases teóricas e metodológicas para repensar os programas curriculares com abordagens integradas de resolução de problemas no domínio do ensino e da pesquisa. Nesse sentido, dá exemplos de projetos de formação científica e pedagógica como a Metodologia da Problematização, a Aprendizagem Baseada em Problemas e Práticas Surpreendentes, como alternativas para refletir sobre a diversidade dos modos de aprender.

São propostas que se conectam às ideias de Olsson (2013, p. 232-233), explicitadas em projeto proposto e desenvolvido pela autora e sua equipe de pesquisadores. Embora tenha sido desenvolvido de modo presencial com crianças em uma instituição de educação infantil, pensamos que o mesmo princípio de trabalho pode ser adotado por estagiários, dado que a educação infantil e a arte possuem conexões por trabalharem com a experiência artística. Esse princípio é o de questionar o conhecimento estabelecido e adotar a emergência do interesse de estudantes na condução das aprendizagens, e baseia-se no conceito filosófico de "evento", tal como formulado por Deleuze e Guattari (Olsson, 2012, p. 88). A autora propõe, nesse projeto, a "eventização" do currículo, colocando-o como alternativa a um modo de atuar na educação que concebe o conhecimento como algo estável e permanente, já dado de antemão. A eventização, dessa forma, pode ser um caminho para desenvolver um trabalho que objetiva descobrir o tipo de relação que crianças - e jovens e, também, estagiários - têm com o que sabem e com o que estão aprendendo, numa ideia de aprendizagem como produção de sentido que é atribuído por esses próprios sujeitos.

Essa é uma ideia que se associa e se amplia com o pensamento de Paulo Freire (2011, p. 134), que sublinha a importância do contorno geográfico, ecológico, social e econômico para a atividade pedagógica. Conhecer a realidade dos alunos é imprescindivel para a ação docente, pois confere sentidos a quem aprende, e não apenas a quem ensina. Por sua vez, Pérez Gómez (2015, p. 29), ao analisar o hábito da multitarefa das novas gerações, destaca que "a quantidade infinita e interminável de informação exige uma intensa tarefa de seleção, foco e concentração". Cabe aos professores valorizar essa realidade e, para isso, destaca o autor, é "imprescindivel aprender a sintetizar, agrupar, organizar e categorizar sem desnaturalizar a complexidade dos âmbitos reais" (Pérez Gómez, 2015, p. 80).

Os desafios para a formação de professores ultrapassam a necessidade de prepará-los para o uso instrumental das tecnologias, questões essas que antecedem a pandemia. Portanto, o desafio não está em aprender o digital, mas na convergência dos saberes para abandonar a lógica disciplinar (Morin, 2000, p. 35-46), construir novas formas para pensar a presença e a educação 
sem distância (Nóvoa, 2020), desenvolver estratégias integradoras entre as diferentes gerações de tecnologias de linguagem e de comunicação (Santaella, 2010, p. 21-22), transformar as escolas em poderosos cenários de aprendizagem (Pérez Gómez, 2015, p. 29) e preparar culturalmente a futura geração para que possa construir sua autonomia e contribuir para um mundo melhor (Figueiredo, 2016, p. 19-21), atuando de um modo colaborativo, amparado na construção compartilhada de saberes e no exercício da cidadania.

\section{CONSIDERAÇÕES FINAIS}

O estágio curricular supervisionado é etapa central em importância na formação de licenciandos em música e, sem dúvida alguma, em qualquer outra licenciatura. É o momento em que os conhecimentos musicais, pedagógicos e pedagógico-musicais são movimentados, colocados em ação e se constituem em temáticas de reflexões para professores e estudantes. Orientados individualmente ou em duplas, e apoiados por disciplinas nas quais grupos de estagiários se encontram para pensar as questões docentes e discutir as especificidades de cada campo de atuação, o estágio supervisionado assume sua vertente formativa e reflexiva tão cara à formação acadêmico-profissional em música.

Foi sobre essa temática que este artigo se debruçou com o objetivo de lançar reflexões sobre estágios não presenciais, evidenciando as desafiantes condições humanas e pedagógicas colocadas pela pandemia, e os caminhos encontrados para dar prosseguimento à formação de licenciandos em música. Se as incertezas nos tomaram de assalto quando propusemos sua retomada no modo remoto, reconhecê-las foi o primeiro e importante passo para não ficarmos paralisadas por termos perdido a linha tênue de nossas certezas fundadas em um fazer escola que não era mais possivel frente à gravidade dessa pandemia.

Para seguirmos em frente foi essencial nos debruçarmos no planejamento e na proposição de um projeto de estágio para ser desenvolvido no aqui e agora, para enfrentar essa aventura incerta. Ao ser preparada, essa proposta buscou a flexibilidade necessária para que os licenciandos pudessem lidar a distância com os distintos contextos marcados pelas desigualdades sociais com que a escola pública tem se deparado e que ficaram ainda mais evidenciadas diante da maior política de isolamento social já vista.

A adoção de aulas remotas foi a possibilidade existente para a continuidade dos estágios e da relação pedagógica e humana entre professores e estagiários, e desses em suas atuações nas escolas. No entanto, os desafios foram e continuam sendo muitos, como, por exemplo, a dificuldade de crianças e jovens de terem acesso aos meios para colocar em prática os processos de ensino e aprendizagem e a limitação para as práticas musicais em grupo. Esses dois pontos têm sido trazidos para discussões e se constituem em objeto de reflexões em um processo cujo fim poderemos começar a vislumbrar, ainda que ao longe. 
Escolhemos o risco de pensar e propor esse caminho porque acreditamos que o momento também é formativo para os estagiários, pois eles serão os professores que, no futuro, talvez tenham que ser criativos e propositivos para dar continuidade às relações com seus próprios alunos em momentos desafiadores tais como este que estamos vivendo na pandemia. A música e suas práticas ganham significados renovados em encontros que, ainda que feitos a distância física, possibilitam que os estagiários se formem professores nesse novo processo de partilha de saberes e fazeres musicais com professores supervisores, e desses com suas crianças e jovens. Ao planejar modos de aprender música enquanto a fazem e escutam, esses encontros também contribuem para deixar menos angustiante um momento como este que estamos vivendo, de desafios diários marcados pelas incertezas.

Nas escolhas feitas, não ficou de fora o nosso compromisso de devolvermos à escola pública de educação básica o conhecimento que temos construido na universidade e, principalmente, no campo da educação musical. Nosso compromisso é também de natureza ética porque reafirmamos que a escola e a universidade, públicas e gratuitas, são direitos fundamentais de crianças e jovens brasileiros, e espaços nos quais devem ter lugar garantido o pensar científico, autônomo e criativo, bem como onde se constrói a participação cidadã.

Com isso, este artigo não finaliza trazendo resultados, mas abrindo um espaço importante de discussão para refletirmos acerca da importância de trabalhos colaborativos como esse que estamos desenvolvendo no trânsito entre universidade e escolas públicas de educação básica. Além disso, para pensarmos as aulas remotas emergenciais e seus impactos para a educação e, em especial, para os estágios curriculares supervisionados dos licenciandos em música. Sublinhamos a escola como um espaço identitário de formação e profissionalização que não pode ser substituído, porém em um contexto de crise são fundamentais ações e discussões que ampliem e fortaleçam a valorização da educação.

\section{REFERENCIAS}

ARRUDA, Eucidio Pimenta. Educação remota emergencial: elementos para políticas públicas na educação brasileira em tempos de Covid-19. EmRede, [s. l.], v. 7, n. 1, p. 257-275, 2020. Disponivel em: https://www.aunirede. org.br/revista/index.php/emrede/article/view/621/575. Acesso em: 6 jan. 2020.

BRASIL. Ministério da Educação. Portaria $n^{\circ}$ 345, de 19 de março de 2020. Altera a Portaria MEC n ${ }^{\circ} 343$, de 17 de março de 2020a. Diário Oficial da União: seção 1, Brasília, ano 158, n. 54-D, p. 1., 19 mar. 2020. Disponivel em: https://pesquisa.in.gov.br/imprensa/jsp/visualiza/index. jsp?jornal $=603 \&$ pagina $=1 \& d a t a=19 / 03 / 2020 \&$ totalArquivos $=1$. Acesso em: 21 jan. 2021. 
BRASIL. Ministério da Educação. Parecer CNE/CP $n^{\circ}$ 5/2020. Brasília: MEC, 2020b. Disponivel em: http://portal.mec.gov.br/index.php?option=com_doc man\&view=download\&alias $=145011-$ pcp005-20\&category_slug=marco2020-pdf\&Itemid=30192. Acesso em: 21 jan. 2021.

Ministério da Educação. Portaria n ${ }^{\circ}$ 544, de 16 de junho de 2020. Dispõe sobre a substituição das aulas presenciais por aulas em meios digitais, enquanto durar a situação de pandemia do novo coronavírus Covid-19, e revoga as Portarias MEC n ${ }^{\circ} 343$, de 17 de março de 2020, $\mathrm{n}^{\circ} 345$, de 19 de março de 2020, e $\mathrm{n}^{\circ} 473$, de 12 de maio de 2020. Diário Oficial da União: seção 1, Brasília, ano 158, n. 114, p. 62., 17 jun. 2020c. Disponivel em: https://pesquisa.in.gov.br/imprensa/jsp/visualiza/index. jsp?data $=17 / 06 / 2020 \&$ jornal $=515 \&$ pagina $=62 \&$ totalArquivos $=98$. Acesso em: 21 jan. 2021.

EKEDAHL, Per; MATEIRO, Teresa. Motivations and intentions to carry out didactic concerts for children. Perspectives: journal of the Early Childhood Music \& Movement Association, [s. l.], v. 10, n. 4, p. 4-8, 2015. Disponivel em https://www.ingentaconnect.com/contentone/intellect/ per/2015/00000010/00000001/art00011. Acesso em: 6 jan. 2020.

ESTRELLA, B.; LIMA, L. CNE aprova diretrizes para escolas durante a pandemia. Portal MEC, Brasília, 28 abr. 2020. Disponível em: http:// portal.mec.gov.br/busca-geral/ 12-noticias / acoes-programas-e-projetos637152388/89051-cne-aprova-diretrizes-para-escolas-durante-a-pandemia. Acesso em: 8 jan. 2021.

FIGUEIREDO, António Dias de. Por uma escola com futuro... para além do digital. Nova Ágora, [s. l.], n. 5, p. 19-21, set. 2016. Disponivel em: https:// www.researchgate.net/publication/309124131_Por_uma_escola_com_ futuro_para_alem_do_digital. Acesso em: 19 dez. 2020.

FREIRE, Paulo. Pedagogia da autonomia: saberes necessários à prática educativa. São Paulo: Paz e Terra, 2011.

LEMOS, André. Cidade e mobilidade. Telefones celulares, funções pósmassivas e territórios informacionais. Matrizes, São Paulo, v. 1, n. 1, p. 121 137, 2007. Disponivel em: https://www.revistas.usp.br/matrizes/issue/ view/3168. Acesso em: 18 dez. 2020.

MATEIRO, Teresa. Sobre os modos de aprender e ensinar: alternativas para a formação docente em música. In: MOGLIORINI, Jeanine Mafra (org.). Reflexões sobre arte e seu ensino. Ponta Grossa: Atena, 2018. p. 103-118. Disponivel em: https://www.atenaeditora.com.br/post-artigo/2772. Acesso em 18 dez. 2020. 
MATEIRO, Teresa; CUNHA, Sandra. Estágios curriculares supervisionados em música: uma aventura incerta. In: ENCONTRO REGIONAL SUL DA ASSOCIAÇÃO BRASILEIRA DE EDUCAÇÃO MUSICAL, 19., 2020, [online]. Anais [...]. [s. l.]: Abem, 2020. p. 1-13. Disponivel em: http://abemsubmissoes.com.br/index.php/RegSul2020/sul/paper/view/407 / 427. Acesso em: 19 mar. 2021.

MORIN, Edgar. Os sete saberes necessários à educação do futuro. 2. ed. São Paulo: Cortez; Brasília: Unesco, 2000.

NÓVOA, Antonio. Formação de professores em tempo de pandemia. [Webconferência]. [S. l.]: Instituto Iungo, 23 jun. 2020. Disponivel em: https://www.youtube.com/watch?v=ef3YQcbERiM\&t=346s. Acesso em: 23 jun. 2020.

NÓVOA, Antonio; ALVIM, Yara. Nothing is new, but everything has changed: a viewpoint on the future school. Prospects, [s. l.], v. 45, p. 35-41, 2020. Disponível em: https://doi.org/10.1007/s11125-020-09487-w. Acesso em: 17 jul. 2020.

OLSSON, Liselott Mariett. Eventicizing curriculum: learning to read and write through becoming a citizen of the world. Journal of Curriculum Theorizing, Indianapolis, v. 28, n.1, p. 88-107, 2012. Disponivel em: https://journal.jctonline.org/index.php/jct/article/view/173. Acesso em: 20 jan. 2021.

. Taking children's questions seriously: the need for creative thought. Global Studies of Childhood, [s. l.], v. 3, n. 3, p. 230-253, 2013. Disponivel em: https://journals.sagepub.com/doi/pdf/10.2304/gsch.2013.3.3.230. Acesso em: 20 jan. 2021.

PACHECO, José. Dicionário de valores. São Paulo: Edições SM, 2012.

Escola da ponte: formação e transformação da educação. 6. ed. Petrópolis: Vozes, 2014.

PÉREZ GÓMEZ, Ángel I. Educação na era digital: a escola educativa. Porto Alegre: Penso, 2015.

SANTA CATARINA. Conselho Estadual de Educação. Resolução CEE/ SC n. 009, de 19 de março de 2020. Dispõe sobre o regime especial de atividades escolares não presenciais no Sistema Estadual de Educação de Santa Catarina, para fins de cumprimento do calendário letivo do ano de 2020, como medida de prevenção e combate ao contágio do Coronavírus (COVID-19). Florianópolis: CEE, 19 mar. 2020a. Disponivel em: http:/ /www. cee.sc.gov.br/index.php/acordo-de-cooperacao/1808-resolucao-009-1/file. Acesso em: 21 jan. 2021. 
SANTA CATARINA. Conselho Estadual de Educação. Parecer CEE/SC n. 222. Florianópolis: CEE, 12 maio 2020b. Disponivel em: http://www.cee.sc.gov. br/index.php/downloads/documentos-diversos/normas-de-enfrentamentoao-covid-19/1841-parecer-2019-222-cee-sc/file. Acesso em: 21 jan. 2021.

Conselho Estadual de Educação. Resolução CEE/SC n. 049, de 22 de junho de 2020. Dá nova redação ao art. $2^{\circ}$ e revoga o $\S 4^{\circ}$ do art. $3^{\circ}$ da Resolução CEE/SC n 009/2020 e aplica ao Sistema Estadual de Educação de Santa Catarina o disposto no Parecer CNE/CP n ${ }^{\circ}$ 5/2020. Florianópolis: CEE, 22 jun. 2020c. Disponivel em: http://www.cee.sc.gov.br/index.php/ downloads / documentos-diversos / normas-de-enfrentamento-ao-covid19/1850-resolucao-200-049-cee-sc/file. Acesso em: 21 jan. 2021.

SANTAELLA, Lúcia. A aprendizagem ubíqua substitui a educação formal? Revista de Computação e Tecnologia da PUC-SP, São Paulo, v. 2, n. 1, p. 17-22, 2010.

SINGER, Helena. Gestão democrática do conhecimento: sobre propostas transformadoras da estrutura escolar e suas implicações nas trajetórias dos estudantes. Relatório de pós-doutoramento. 2018. Campinas: Universidade Estadual de Campinas, 2008. Disponivel em https: / www. academia.edu/30667612/A_GEST\%C3\%830_DEMOCR\%C3\%81TICA_ DO_CONHECIMENTO_SOBRE_PROPOSTAS_TRANSFORMADORAS_DA_ ESTRUTURA_ESCOLAR_E_SUAS_IMPLICA\%C3\%87\%C3\%95ES_NAS_ TRAJET\%C3\%93RIAS_DOS_ESTUDANTES. Acesso em: 6 jan. 2020.

(org.). Territórios educativos: experiências em diálogo com o Bairro-Escola. São Paulo: Moderna, 2015a. v. 1. Disponivel em: https:// educacaointegral.org.br/wp-content/uploads/2015/04/TerritoriosEducativos_Vol1.pdf. Acesso em: 06 jan. 2020.

(org.). Territórios educativos: experiências em diálogo com o BairroEscola. São Paulo: Moderna, 2015b. v. 2. Disponivel em: https://www. cidadeescolaaprendiz.org.br/wpcontent/uploads/2015/03/TerritoriosEducativos_Vol2.pdf. Acesso em: 06 jan. 2020.

TARDIF, Maurice. Lições da pandemia para o futuro da educação. [S. l.]: Cenpec Educação, 2020. (Série Vozes Educadoras). Publicado no canal Portal Cenpec. Disponivel em: https://www.youtube.com/ watch?v=Yi4SOiCEUII\&feature=emb_logo. Acesso em: 21 jan. 2021. 
Teresa Mateiro é professora associada do Departamento de Música (DMU) da Universidade do Estado de Santa Catarina (Udesc). Atua nos programas de pós-graduação Mestrado em Música (PPGMUS) e Mestrado Profissional em Artes (Prof-Artes) na mesma instituição. É coordenadora dos Estágios Curriculares Supervisionados do DMU. Foi professora de música em escolas, públicas e privadas, de educação básica. Tem licenciatura e mestrado em Educação Musical pela Universidade Federal do Rio Grande do Sul (UFRGS) e doutorado em Filosofia da Educação pela Universidade do País Vasco, Espanha. Realizou pós-doutorado na Universidade de Lund, Suécia. É líder do Grupo de Pesquisa Educação Musical e Formação Docente (Udesc/CNPq). É editora da revista Orfeu (PPGMUS/Udesc). Desenvolve pesquisas na área de formação docente, privilegiando temas como prática pedagógica, programas curriculares, conhecimento profissional, práticas musicais escolares, estudos transculturais e pesquisa (auto) biográfica em educação musical. https://orcid.org/0000-0002-3527-8366

Sandra Mara da Cunha é professora adjunta do Departamento de Música e do Programa de Pós-Graduação em Música do Centro de Artes da Universidade do Estado de Santa Catarina (Udesc). Líder do grupo de pesquisa mei: música - educação - infância, vinculado ao PPGMUS/Udesc. Doutora em Educação pela Faculdade de Educação da Universidade de São Paulo (USP), com pós-doutorado pela mesma instituição. Mestre em Artes pela Escola de Comunicação e Artes da USP, graduada em Instrumento-Piano, licenciada em Música e especialista em Educação Musical pela Universidade Federal de Goiás (UFG). Os estudos e investigações mais recentes têm se constituído nos diálogos da educação musical com os estudos sociais da infância, com o objetivo de pensar o lugar das crianças na educação musical, em estudos sobre a participação infantil nas aulas de música, em aprendizagens colaborativas intergeracionais e intrageracionais. https://orcid.org/0000-0002-2952-1796 